\title{
Nucleic acid functionalized extracellular vesicles as promising therapeutic systems for nanomedicine
}

\author{
Chunping Liư ${ }^{1,2}$, Dongyue He ${ }^{1}$, Huan Cen ${ }^{1}$, Huiqi Chen ${ }^{1}$, Longmei Li ${ }^{1}$, Guangning Nie ${ }^{1}$, Zixue Zhong ${ }^{1}$, \\ Qingfeng He ${ }^{1}$, Xiaofei Yang ${ }^{1}$, Sien Guo ${ }^{1}$, Lei Wang ${ }^{1}$, Zhijin Fan ${ }^{3,4}$
'State Key Laboratory of Dampness Syndrome of Chinese Medicine, The Second Affiliated Hospital of Guangzhou University of Chinese Medicine, Guangzhou 510080, Guangdong, China.
${ }^{2}$ State Key Laboratory of Quality Research in Chinese Medicine, Institute of Chinese Medical Sciences, University of Macau, Macau 999078, China.
${ }^{3}$ Molecular Diagnosis and Treatment Center for Infectious Diseases, Dermatology Hospital, Southern Medical University, Guangzhou 510091, Guangdong, China.
${ }^{4}$ School of Medicine, South China University of Technology, Guangzhou 510006, Guangdong, China.

\begin{abstract}
Correspondence to: Zhijin Fan, School of Medicine, South China University of Technology, Guangzhou 510006, Guangdong, China. E-mail: mcfanzhijin@mail.scut.edu.cn; Dr. Lei Wang, State Key Laboratory of Dampness Syndrome of Chinese Medicine, The Second Affiliated Hospital of Guangzhou University of Chinese Medicine, Guangzhou 510080, Guangdong, China.

E-mail: Dr.wanglei@gzucm.edu.cn
\end{abstract}

\begin{abstract}
How to cite this article: Liu C, He D, Cen H, Chen H, Li L, Nie G, Zhong Z, He Q, Yang X, Guo S, Wang L, Fan Z. Nucleic acid functionalized extracellular vesicles as promising therapeutic systems for nanomedicine. Extracell Vesicles Circ Nucleic Acids 2022;3:14-30. https://dx.doi.org/10.20517/evcna.2021.21
\end{abstract}

Received: 29 Nov 2021 First Decision: 14 Jan 2022 Revised: 28 Jan 2022 Accepted: 14 Feb 2022 Published: 22 Feb 2022

Academic Editors: Yoke Peng Loh, Cheng Jiang Copy Editor: Xi-Jun Chen Production Editor: Xi-Jun Chen

\begin{abstract}
Extracellular vesicles (EVs), as natural carriers, are regarded as a new star in nanomedicine due to their excellent biocompatibility, fascinating physicochemical properties, and unique biological regulatory functions. However, there are still some challenges to using natural EVs, including poor targeting ability and the clearance from circulation, which may limit their further development and clinical use. Nucleic acid has the functions of programmability, targeting, gene therapy, and immune regulation. Owing to the engineering design and modification by integrating functional nucleic acid, EVs offer excellent performances as a therapeutic system in vivo. This review briefly introduces the function and mechanism of nucleic acid in the diagnosis and treatment of diseases. Then, the strategies of nucleic acid-functionalized $\mathrm{EV}$ s are summarized and the latest progress of nucleic acid-functionalized EVs in nanomedicine is highlighted. Finally, the challenges and prospects of nucleic acidfunctionalized EVs as a promising diagnostic system are proposed.
\end{abstract}


Keywords: Extracellular vesicles, nucleic acid, nanomedicine, mRNA vaccine, aptamer

\section{INTRODUCTION}

Extracellular vesicles (EVs) are natural nano-carriers produced by living cells for intercellular communication $^{[1-3]}$. EVs can be classified as exosomes, microvesicles, or apoptotic bodies according to their biogenesis type and particle size ${ }^{[4]}$. Exosomes and microvesicles are the most widely studied, thus "EV" is commonly used to refer to these two subgroup $\mathrm{s}^{[\mathrm{s}]}$. Exosomes, with particle sizes ranging from 30 to $150 \mathrm{~nm}$, are formed when multivesicular bodies fuse with the cell membrane and release the vesicles inside ${ }^{[6]}$. Microvesicles, with particle sizes of $50-1000 \mathrm{~nm}$, are formed by cell membrane bubbling ${ }^{[6]}$. Due to the limitation of the separation method, exosomes and microvesicles are difficult to separate in the range of 30$200 \mathrm{~nm}$, which are commonly referred to collectively as small EVs. The EVs summarized in this paper mainly refer to small EVs, including exosomes and microvesicles. Due to their good biocompatibility, low immunogenicity, excellent extensibility, and unique biological regulatory function, EVs have attracted wide attention in the field of nanomedicine and are considered as a new star in nanomedicine ${ }^{[7-9]}$.

EVs have been developed as a delivery carrier of drugs or contrast agents, showing great application potential in the field of disease diagnosis and treatment ${ }^{[5,8,9]}$. However, native EVs have difficulty meeting the functional requirements of the complex physiological environment; therefore, necessary engineering design and modification can significantly improve the performance of EVs as a therapeutic system. As biological macromolecules, nucleic acid has unique biological functions and has been widely used in the field of nanomedicine $e^{[10-13]}$. RNA interference, antisense oligonucleotides, and cluster regularly spaced short palindromic repeats-associated protein 9 (CRISPR/Cas9) system can downregulate, enhance, or correct gene expression and have wide application potential in gene therapy research ${ }^{[14-19]}$. Nevertheless, these promising therapies are severely limited by inefficient biological distribution and sensitivity to degradation. The development of intracellular delivery carriers can effectively overcome the above limitations of nucleic acid therapy. EVs are natural carriers of information, matter, and energy exchange between cells, involving molecular transport between cells. Functional genetic components such as DNA, mRNA, and ncRNA loaded by EVs can be transported to target cells to perform the function of gene expression regulation. This suggests that EVs are a good nucleic acid delivery carrier. The combination of nucleic acid and EVs makes up for their shortcomings and is expected to provide a promising diagnosis and treatment system for nanomedicine. In addition, nucleic acids also have targeting (aptamer), programmability, drug loading, and immunomodulatory functions ${ }^{[20]}$, which will greatly improve the application prospects of EVs.

This review briefly summarizes the function and mechanism of nucleic acid in diagnosis and treatment and preliminarily clarifies the necessity and advantages of nucleic acid-functionalized EVs. This review provides a basic understanding of this field by highlighting the engineering strategies and representative progress (Scheme 1). Finally, the challenges and future development of nucleic acid-functionalized EVs are proposed.

\section{FUNCTION AND MECHANISM OF NUCLEIC ACID IN NANOMEDICINE}

As biological macromolecules, nucleic acid has unique biological functions and has been widely used in the field of nanomedicine ${ }^{[21-23]}$. Among them, the most common functions are targeting, programming, gene expression regulation, and immune regulation. This section briefly introduces the functions and mechanisms of nucleic acid [Figure 1]. Related studies on the use of nucleic acid in the biomedical field can also be found in earlier literature ${ }^{[24,25]}$. 


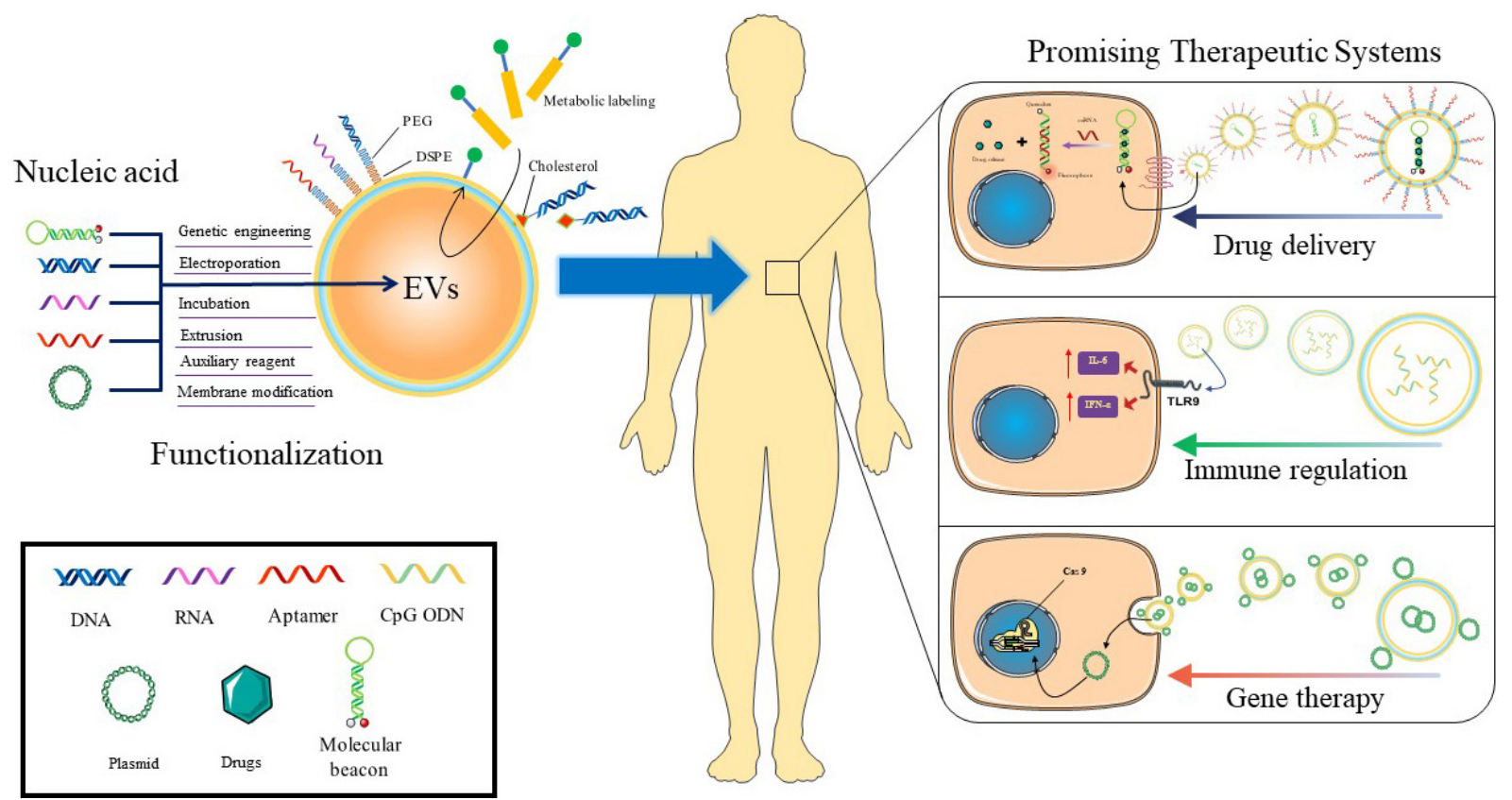

Scheme 1. Nucleic acid-functionalized EVs are promising therapeutic systems for nanomedicine. As a functional macromolecule, nucleic acid has the capabilities of targeting, self-assembly, drug loading, gene editing, and immune regulation. By combining nucleic acid with $\mathrm{EV}$ s, EVs acquire the functional properties of nucleic acid, thus showing unprecedented application potential in drug delivery, immune regulation, and gene therapy, which are expected to provide a promising therapeutic system. EVs: Extracellular vesicles.

\section{Targeting ability}

Aptamers are oligonucleotide sequences with specific affinity activity screened by the systematic evolution of ligands by exponential enrichment technique. The obtained oligonucleotide sequences with specific recognition and affinity for proteins, bacteria, cells, and other target molecules are also called chemical antibodies $^{[26,27]}$. Aptamers can be used as drugs themselves or combined with drugs, siRNA, and nanoparticles to form targeted drug delivery systems, which can target specific tumor cells, reduce toxicity to normal cells, significantly reduce drug dosage, and improve efficacy ${ }^{[28-31]}$. Aptamers have become valuable affinity probes in biochemistry research, disease diagnosis, and treatment. Recently, Wang et al. ${ }^{[32]}$ developed a DNA adapter with excellent targeting properties and unique functional versatility that can be used for biomarker detection, medical molecular imaging, and therapeutic targeted drug delivery. In another study, Liu et al. ${ }^{[33]}$ developed a fluorescent probe based on DNA aptamer for specific molecular typing of mammary neoplasms. Aptamers for new targets are being screened, providing new options for targeted therapy.

The aptamer, as a specific recognition element, has the advantages of simple synthesis, easy modification, biodegradability, and low toxicity, and it has aroused wide attention in both basic and clinical research ${ }^{[28]}$. In particular, some aptamers for surface biomarkers of cancer have been screened out and used in the design of targeted delivery systems for cancer ${ }^{[34-36]}$. With the development of technology, aptamers can be modified by various functional groups, which will further expand the application prospects of aptamers.

\section{Drug delivery carriers}

Nucleic acids have the property of self-assembly, and they can be assembled into a double helix structure through complementary pairs of bases, or complex structures such as G-quadruplets can be constructed through complementary pairs of bases ${ }^{[37,38]}$. DNA origami technology uses the folding and self-assembly of nucleic acids such as DNA and RNA to form complex structures ${ }^{[39,40]}$. DNA origami technology can 


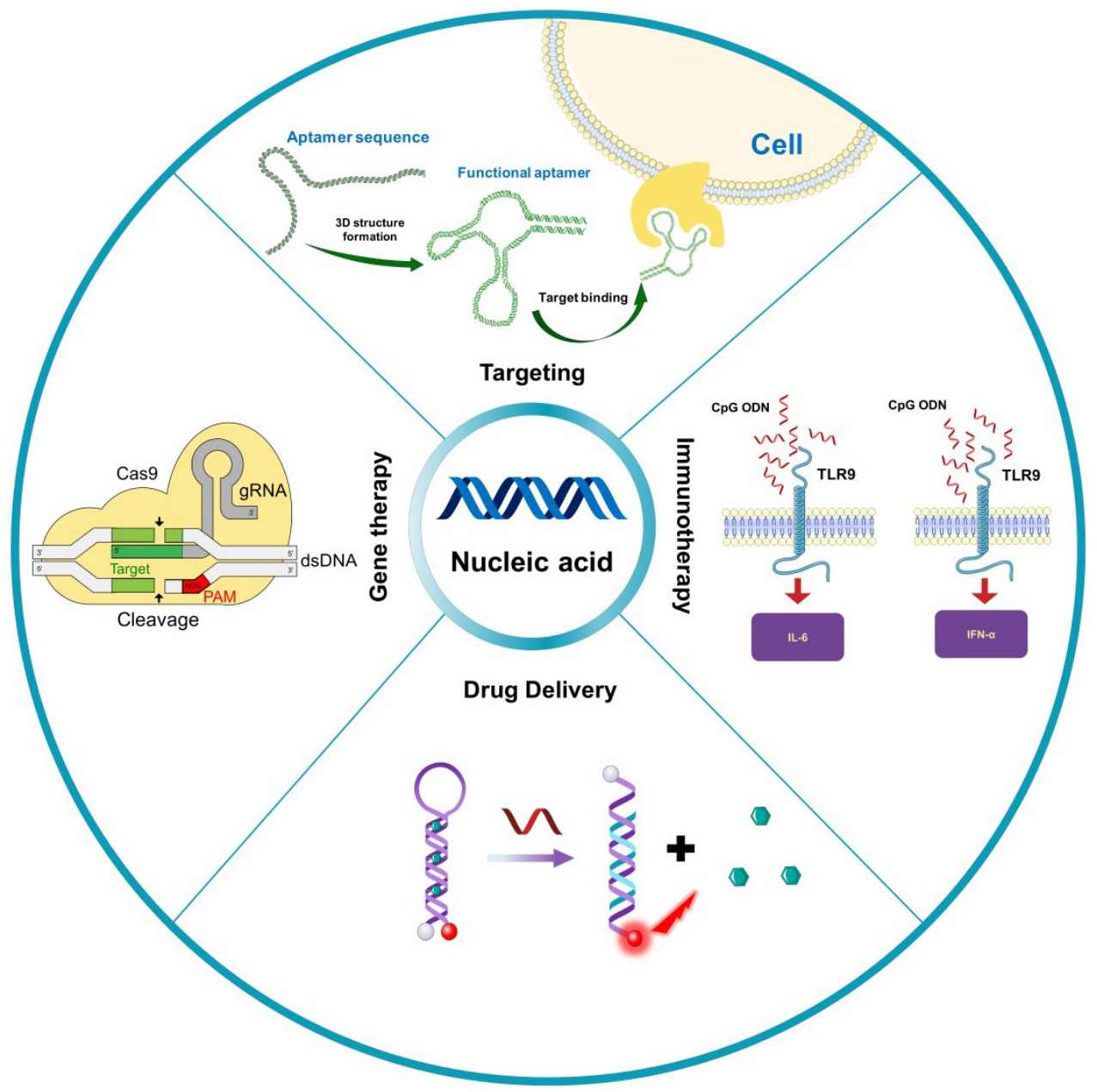

Figure 1. Function and mechanism of nucleic acid in nanomedicine. Nucleic acid has the characteristics of targeting (aptamer), immune regulation (CpG OND), drug delivery (molecular beacon or DNA origami), and gene editing (CRISPR/Cas9). CRISPR/Cas9: Cluster regularly spaced short palindromic repeats-associated protein 9.

synthesize homogeneous nanostructures with sizes between 50 and $400 \mathrm{~nm}$ that can be used as drug delivery materials to enhance drug delivery and survival in malignant environments ${ }^{[40-43]}$. DNA origami technology can also design dynamic, multi-stimulus responsive nanostructures to achieve controlled release of drugs ${ }^{[44,45]}$. Jiang et al. ${ }^{[46]}$ used DNA origami to deliver adriamycin into the body. They found that drugloaded DNA triangle origami showed a strong tumor treatment effect, and no systemic side effects were observed when treating human MDA-MB-231 breast tumor cells ${ }^{[47]}$. As an effective and biocompatible drug carrier, DNA origami has great potential in tumor therapy ${ }^{[41,48-53]}$.

In addition to DNA origami, there are other types of nucleic acid drug carriers. Molecular beacons are fluorescently labeled stem-loop oligonucleotide chains capable of loading and transporting doxorubicin ${ }^{[54]}$. The advantage of molecular beacons as drug carriers is that drug release requires conditions to trigger the destruction of nucleic acid secondary structure, and the drug release process can be monitored in real time by fluorescence signal. For example, Ma et al. ${ }^{[55]}$ reported a drug delivery system based on molecular beacon for detecting telomerase activity and telomerase triggered drug release in living cells. This provides a feasible strategy for conditionally controlled release and treatment monitoring. DNA hydrogel is a new kind of important DNA material, which is a three-dimensional polymer network constructed by DNA as a 
structural element ${ }^{[5]}$. It has been used extensively to develop drug delivery systems (DDS) because of its advantages of high water content, large drug loading space, and good biocompatibility ${ }^{[57]}$. To sum up, the nucleic acid drug carrier has the advantage of being programmable, showing great application potential in the construction of DDS.

However, naked nucleic acid nanostructures have relatively high electrical charges, which may influence their behavior in blood circulation and scavenging. Additionally, the DNA nanostructure has a potential immune risk, being it easy to trigger the body's inflammatory response. Polymer coating protects nucleic acid drug carriers from overexposure and has been shown to improve structural integrity and circulatory stability as well as to attenuate immune stimulation.

\section{Gene therapy}

Gene therapy, as an indispensable tool in biomedical research, has shown potential to treat a variety of diseases, including single-gene inherited diseases, cancer, cardiovascular disease, diabetes, infectious diseases, and inflammatory diseases, which has profoundly influenced the development of medicine. Gene therapy is the treatment of diseases by introducing genetic material into cells and editing genes that produce defective proteins or interfering with gene expression ${ }^{[58]}$. Nucleic acids are the main tools of gene therapy, such as DNA and mRNA molecules for gene overexpression and small RNA molecules such as siRNA, miRNA, and antisense oligonucleotides for gene knockdown ${ }^{[50]}$. For example, Kusano et al. ${ }^{[60]}$ reported the potential therapeutic effect of intramuscular sonic hedgehog gene transfer on myocardial injury repair. In recent years, gene editing strategies based on the CRISPR/Cas9 system have been applied to the treatment of genetic diseases. The CRISPR/Cas9 system needs to guide nucleic acid sequence to control gene editing sites and is also a representative of nucleic acid participation in gene therapy ${ }^{[6]]}$. The biggest limitation of gene therapy is the efficient delivery of gene regulatory systems to cells. Nucleic acid in its natural form is not easily absorbed by cells and is easily degraded and removed, so carriers are needed to deliver nucleic acid into cells. Although viral vectors such as adenoviruses, lentiviruses, and retrovirus show advantages in transfection rates and life-long expression, insertional mutations and other persistent side effects make clinical use difficult. EVs have nucleic acid and protein delivery functions and are potential gene therapy vectors.

\section{Immune regulation}

Nucleic acid has the potential for immune regulation. In the process of biological evolution, higher organisms have evolved the mechanism of recognizing microbial nucleic acid sequences through pattern recognition receptors, thus activating anti-infection immunity ${ }^{[2]}$. This provides the basis for the immune regulation of nucleic acids. $\mathrm{CpG}$ oligodeoxynucleotide (CpG ODN) is a commonly used immune adjuvant that can effectively trigger a mammalian immune response through toll-like receptor 9 (TLR9) signaling and has been used as an immune adjuvant against infection and tumor ${ }^{[63-70]}$. In addition, poly I: C, PolyA: U, etc. may enhance the activity of nucleotide kinases and participate in immune regulation ${ }^{[6,71]}$.

In addition to the oligo nucleic acid chain, immune-gene therapy is another important way of nucleic acid immune regulation. It works by introducing genes that promote immune activation into the body's cells. There are two cases. The first is the introduction and expression of cytokine genes to enhance the body's immunity ${ }^{[2,73]}$. This method has broad spectrum and non-specificity. The other is a process that stimulates specific immunity by introducing specific epitope genes into the body. The method is also known as a nucleic acid vaccine (NAV). NAV aimes to introduce the gene sequence encoding specific antigen protein into animal somatic cells, synthesize antigen by using the protein expression system of animal itself, and induce the animal body to produce acquired immunity for the purpose of preventing and treating diseases. DNA vaccines are also known as naked vaccines, so named because they do not require any chemical 
vectors $^{[74]}$. After the DNA vaccine is introduced into the host, it is taken up by cells (tissue cells, dendritic cells, or other antigen-presenting cells), and the antigen protein is expressed by using the protein synthesis system of the cells, which stimulates the host to produce cellular and humoral immunity through a series of cascading processes ${ }^{[5,76]}$. Compared with traditional inactivated vaccine, DNA vaccine has the following advantages: (1) enhanced immune protection; (2) sequence design can be used to modify antigen determinants or prepare polyvalent vaccines; and (3) producing a safe and durable immune response that does not require multiple immunizations. However, DNA vaccines are potentially dangerous: (1) Continuous expression of foreign antigens may have adverse consequences. Long-term expression of exogenous antigen by plasmids may lead to immune tolerance or anesthesia. (2) After being injected into the body, foreign DNA may be integrated into the host genome to inactivate or activate the tumor suppressor genes of the host cells and transform the host cells into cancer cells, which may be the worthiest of in-depth study among many safety issues of the nucleic acid vaccine.

mRNA vaccines can trigger a specific immune response by introducing mRNA encoding specific antigens into the body and using the protein synthesis mechanism of the host cell to produce antigens. Compared with traditional vaccines, mRNA vaccines are simpler to produce, faster to develop, do not require cell culture, have lower $\operatorname{cost}^{[77]}$, and are more immunogenic in expressing conformation stable proteins or exposing key antigen sites ${ }^{[78-82]}$. Even when compared with DNA vaccines, there are significant advantages. mRNA vaccines do not need to enter the nucleus, so they do not carry the risk of integration into the host genome $^{[83]}$. However, two challenges must be overcome before mRNA vaccines work. The first challenge is the design and synthesis of mRNA. The high expression, specificity, and immunogenicity of kernel mRNA are important to the success of vaccines. In addition, mRNA also requires special design and modification to improve its stability. Another important challenge is the construction of a delivery carrier. A carrier with targeted properties can improve the enrichment of mRNA in the target cell, which is conducive to the efficient expression of the antigen. In this process, the lysosomal escape ability of the carrier is equally important for protecting mRNA from degradation. It is exciting that the approval of two coronavirus disease 2019 (COVID-19) mRNA vaccines (mRNA-1273 and BNT162b2) promote the development of mRNA vaccine technology. Clinical trials have shown that the two-dose regimen of BNT162b2 provides 95\% protection against COVID-19 in humans over 16 years of age. Median safety over two months was same as other vaccines ${ }^{[84]}$. However, mRNA vaccines also have some problems to be solved, such as poor stability of the mRNA itself, low cell entry efficiency, and low translation efficiency ${ }^{\left[{ }^{[5]}\right]}$. The development of intracellular delivery carriers with nucleic acid protection has become a research focus in this field ${ }^{[86-88]}$.

\section{ENGINEERING STRATEGIES FOR NUCLEIC ACID-FUNCTIONALIZED EXTRACELLULAR VESICLES}

Nucleic acid has developed into an important functional subassembly for the modification and functionalization of drug delivery carriers due to its unique physiological and biochemical properties. EVs, a rising star in drug delivery, has also sparkled with nucleic acid subassembly. Therefore, it is important to know the strategy of nucleic acid functionalization of EVs. The current engineering strategies of EVs with nucleic acid can be divided into two types: membrane modification and encapsulation. Each type contains several fabrication approaches. Commonly used fabrication approaches and their merits and demerits are summarized in Table 1.

\section{Membrane modification strategies}

By modifying specific chemical groups, the coupling between nucleic acid and EVs can be efficiently realized [Figure 2A]. Hydrophobic molecules such as 1,2-distearoyl-sn-glycero-3-phosphorylethanolamine (DSPE) can be inserted into the phospholipid bilayer of EVs. Nucleic acid molecules can be anchored to the 
Table 1. Comparison of different engineering strategies for nucleic acid-functionalized EVs

\begin{tabular}{|c|c|c|c|c|}
\hline Approach & Components & Merits & Demerits & Ref. \\
\hline $\begin{array}{l}\text { Parental cell } \\
\text { treatment }\end{array}$ & mRNA, SgRNA & $\begin{array}{l}\text { High loading efficiency, no } \\
\text { damage to EVs }\end{array}$ & $\begin{array}{l}\text { The operation is difficult and the process } \\
\text { complex }\end{array}$ & {$[89-91]$} \\
\hline Incubation & SiRNA & $\begin{array}{l}\text { Facile method and easy to } \\
\text { operate }\end{array}$ & Low load efficiency & [92] \\
\hline $\begin{array}{l}\text { Membrane } \\
\text { modification }\end{array}$ & $\begin{array}{l}\text { Aptamer, DNA hinge, CpG ODN, } \\
\text { molecular beacon }\end{array}$ & $\begin{array}{l}\text { Simple operation, high } \\
\text { load efficiency }\end{array}$ & $\begin{array}{l}\text { Nucleic acids are exposed to the surface } \\
\text { and have no protective effect }\end{array}$ & {$[93-95]$} \\
\hline Extrusion & SiRNA & High load efficiency & Complex preprocessing & [96] \\
\hline Electroporation & $\begin{array}{l}\text { CpG ODN, siRNA, molecular } \\
\text { beacon }\end{array}$ & $\begin{array}{l}\text { Simple operation, high } \\
\text { load efficiency }\end{array}$ & $\begin{array}{l}\text { The formation of pores in EVs may cause } \\
\text { irreversible damage }\end{array}$ & {$[94,97,98]$} \\
\hline Sonication & miRNA, siRNA & Simple operation & $\begin{array}{l}\text { Structural failure and low load efficiency for } \\
\text { macromolecules }\end{array}$ & {$[99,100]$} \\
\hline Streptolysin O & DNA junction, molecular beacon & Simple operation & The integrity of EVs may be impaired & {$[101,102]$} \\
\hline Liposome & Plasmid, small RNA & $\begin{array}{l}\text { Simple operation, high } \\
\text { load efficiency }\end{array}$ & $\begin{array}{l}\text { Particle size becomes larger, and EVs } \\
\text { aggregates }\end{array}$ & {$[103,104]$} \\
\hline
\end{tabular}

EVs: Extracellular vesicles; CpG ODN: CpG oligodeoxynucleotides.
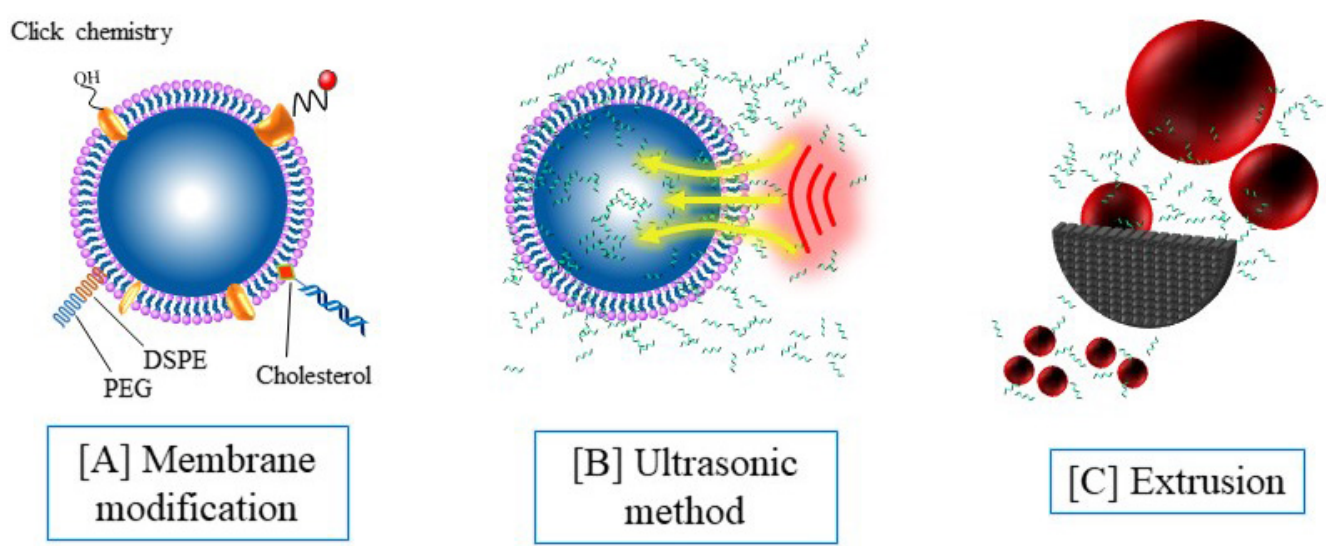

\section{[C] Extrusion}

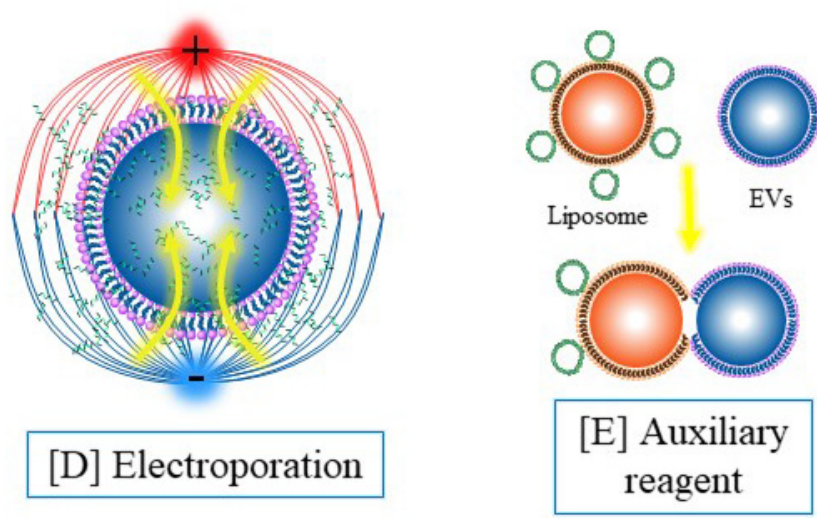

Figure 2. Engineering strategies for nucleic acid-functionalized extracellular vesicles: (A) membrane modification by using 1,2distearoyl-sn-glycero-3-phosphorylethanolamine insertion, click chemistry, and covalent modification; (B) ultrasonic oscillations mediate nucleic acid loading; (C) nucleic acid loading mediated by extrusion; (D) nucleic acid loading mediated by electroporation; and (E) nucleic acid loading mediated by an auxiliary reagent.

surface of the vesicles by nucleic acid coupling DSPE ${ }^{[93]}$. Our previous study found that fresh EVs are rich in sulfhydryl groups, and nucleic acid can be conjugated with EVs by modifying the maleimide group with nucleic acid ${ }^{[94]}$. This method is mild and specific and has a wide application prospect. In recent years, click 
chemical modification based on glucose metabolism chemistry has been introduced into the engineering of $\mathrm{EVs}^{[105-107]}$, which also provides a promising approach for nucleic acid modification. The membrane modification strategies can anchor nucleic acid to the surface of the vesicles, thus endowing the EVs with targeted recognition and other functions. However, these loading methods leave the nucleic acid exposed to the outside of the EVs and cannot obtain the protection of the EVs.

\section{Encapsulation strategies}

In addition to surface modifications, nucleic acid components can also be encased inside EVs [Figure 2B-E]. Parental cell treatment is an early method used to introduce nucleic acids into EVs. Although this method has high efficiency and simple follow-up operation, the preprocessing such as plasmid construction is still tedious and time-consuming. Electroporation is a transfection method that uses electrical pulses to create temporary holes in the plasma membrane to drive charged molecules in by establishing an electric potential in the membrane. Electroporation is an effective nucleic acid loading method and has been widely used in EVs for nucleic acid loading. In our previous work, molecular beacons were loaded into EVs through electroporation with a transfection efficiency at about $60 \%{ }^{[94]}$. It has also been reported that incubation, extrusion, and sonication can induce nucleic acid to enter EVs. However, these methods are widely used in small molecule loading, but not widely used in nucleic acid loading due to their low efficiency for macromolecules. In recent years, the nucleic acid loading method using streptolysin $\mathrm{O}$ and liposome is a potential alternative to electroporation ${ }^{[101]}$. In contrast to membrane modification, encapsulation strategies can isolate nucleic acid from the external environment, avoiding premature exposure and degradation of nucleic acid.

\section{APPLICATION OF NUCLEIC ACID FUNCTIONALIZED EXTRACELLULAR VESICLES IN BIOMEDICINE}

Nucleic acid-functionalized EVs have attracted extensive attention in biomedicine for their outstanding advantages. This section briefly highlights the current representative progress of nucleic acid-functionalized EVs to provide a preliminary understanding for interested researchers. The specific contents are summarized in Table 2.

\section{Nucleic acid-functionalized extracellular vesicles for targeted drug delivery}

EVs have shown fascinating interest in the field of drug delivery and are regarded as promising for the next generation of nanomedicine. However, how to improve active targeting is an important problem for EVs. Aptamers can specifically recognize and bind to targets, showing great application potential in the construction of targeted drug delivery systems. Wan et al. ${ }^{[93]}$ reported targeting exosomes with aptamers carrying paclitaxel, a common anticancer drug in clinical practice. They covalently linked the AS1411 aptamer with cholesterol-PEG and subsequently grafted it onto mouse DC membranes. Then, modified DCs are mechanically extruded to create aptamer-guided nanovesicles. By using this extruding method, $\sim 3 \times 10^{10}$ targeted nanovesicles were obtained from approximately $1 \times 10^{7}$ cells within $1 \mathrm{~h}$. Chloe-PEG2000 was selected because of its amphiphilic and relatively rigid properties, which could stabilize nanovesicles by hydrophobic effect on the lipid bilayer. Strategies for preparing DSPE-aptamers may be used to mass produce targeted exosomes secreted by immune cells for cancer treatment. The approach is considered safer than cell-based immunotherapies because the vesicles have lost their ability to expand ${ }^{[93]}$.

Guo's team reprogrammed exosomes using aptamer localization on the surface of exosomes to guide siRNA/miRNA cargo for targeted delivery and cancer treatment ${ }^{[115]}$. The authors designed a nanostructure with a three-way connection to make the ligands locate onto the interface of EVs. Placing membraneanchored cholesterol at the tail of the three-way connection causes RNA aptamers or folic acid to appear on 
Table 2. An overview of nucleic acid-functionalized EVs in nanomedicine.

\begin{tabular}{|c|c|c|c|c|c|c|c|}
\hline $\begin{array}{l}\text { NA } \\
\text { type }\end{array}$ & Function & EV origin & $\begin{array}{l}\text { Loading } \\
\text { strategy }\end{array}$ & Composition & Disease target & Outcomes & Ref. \\
\hline \multirow[t]{4}{*}{ ncRNA } & $\begin{array}{l}\text { Regulate gene } \\
\text { expression }\end{array}$ & $\mathrm{MSCs}$ & $\begin{array}{l}\text { Parent cell } \\
\text { treatment }\end{array}$ & Exogenous miR-let7c & Renal fibrosis & miR-let7c-MSC therapy attenuated kidney injury & [108] \\
\hline & $\begin{array}{l}\text { Regulate gene } \\
\text { expression }\end{array}$ & HEK 293T & $\begin{array}{l}\text { Parent cell } \\
\text { treatment }\end{array}$ & circRNA & Depressive-like behaviors & $\begin{array}{l}\text { Efficiently delivered circDYM to the brain and alleviated } \\
\text { CUS-induced depressive-like behaviors }\end{array}$ & [109] \\
\hline & $\begin{array}{l}\text { Regulate gene } \\
\text { expression }\end{array}$ & DCs & Electroporation & miR-let7 & Breast cancer & $\begin{array}{l}\text { Selectively targeted tumor tissues in tumor-bearing mice } \\
\text { and inhibited tumor growth }\end{array}$ & [110] \\
\hline & $\begin{array}{l}\text { Regulate gene } \\
\text { expression }\end{array}$ & MDA-MB231 & $\begin{array}{l}\text { Parent cell } \\
\text { treatment }\end{array}$ & miRNA and siRNA & NA & Significantly reduced its therapeutic dose & {$[111]$} \\
\hline \multirow[t]{5}{*}{ siRNA } & $\begin{array}{l}\text { Interfering gene } \\
\text { expression }\end{array}$ & $\begin{array}{l}\text { Normal human fore-skin } \\
\text { fibroblast }\end{array}$ & Electroporation & Alexa Fluor 647-tagged siRNA & KRAS $^{\text {G12D }}$ & $\begin{array}{l}\text { Suppressed cancer in multiple mouse models of } \\
\text { pancreatic cancer and significantly increased overall } \\
\text { survival }\end{array}$ & [98] \\
\hline & $\begin{array}{l}\text { Interfering gene } \\
\text { expression }\end{array}$ & Neuro2A cells or DCs & Co-incubation & Cholesterol-conjugated siRNAs & Human antigen $\mathrm{R}$ & $\begin{array}{l}\text { Facilitated concentration-dependent silencing of human } \\
\text { antigen R }\end{array}$ & [112] \\
\hline & $\begin{array}{l}\text { Interfering gene } \\
\text { expression }\end{array}$ & $\begin{array}{l}\text { Umbilical-cord-derived } \\
\text { mesenchymal stem cells }\end{array}$ & Co-incubation & Hydrophobically modified siRNA & Huntingtin mRNA & $\begin{array}{l}\text { Significant bilateral silencing of up to } 35 \% \text { of Huntingtin } \\
\text { mRNA }\end{array}$ & [113] \\
\hline & $\begin{array}{l}\text { Interfering gene } \\
\text { expression }\end{array}$ & HEK293T cells & Co-incubation & siRNA & Survivin gene & Significantly suppressed KB cell-derived cancer & [114] \\
\hline & $\begin{array}{l}\text { Interfering gene } \\
\text { expression }\end{array}$ & HEK293T cells & Transfection & $\begin{array}{l}\text { siRNA with 3WJ-folate arrow } \\
\text { siRNA with 3WJ-cholesterol arrow }\end{array}$ & Survivin gene & Suppressed tumor growth in three animal models & {$[115]$} \\
\hline \multirow[t]{2}{*}{ mRNA } & Coding protein & $\begin{array}{l}\text { Mouse embryonic } \\
\text { fibroblasts }\end{array}$ & Electroporation & mRNA & $\begin{array}{l}\text { Phosphatase and tensin } \\
\text { homologue-deficient glioma }\end{array}$ & $\begin{array}{l}\text { RNA-containing exosomes restored tumor-suppressor } \\
\text { function, enhanced inhibition of tumor growth, and } \\
\text { increased survival }\end{array}$ & [116] \\
\hline & Coding protein & HEK293 & $\begin{array}{l}\text { Parent cell } \\
\text { treatment }\end{array}$ & mRNA & Cerebral ischemia & Reduced inflammation and promoted cell survival & {$[90]$} \\
\hline \multirow[t]{6}{*}{ DNA } & Gene therapy & HEK293T cells & Transfection & $\begin{array}{l}\text { Plasmid/DNA aptamers } \\
\text { Pgc1 } 1 \text { and II-10 mRNA }\end{array}$ & PGC1 $\alpha$ & $\begin{array}{l}\text { Delivery of Pgc1 } \alpha \text { or II-10 mRNA efficiently induced white } \\
\text { adipocyte browning and alleviated IBD, respectively }\end{array}$ & [117] \\
\hline & Immunotherapy & HEK293T cells & Transfection & Plasmid encoding Gag-OVA & $\mathrm{CD}_{4}^{+}$and $\mathrm{CD} 8^{+} \mathrm{T}$-cell & $\begin{array}{l}\text { Facilitated antigen cross-presentation and improved } \\
\text { induced immunity }\end{array}$ & [118] \\
\hline & Gene therapy & $4 \mathrm{~T} 1$ cells & Transfection & Minicircle DNA & TK-NTR & $\begin{array}{l}\text { Mediated gene transfer that enables effective prodrug } \\
\text { conversion and tumor cell death }\end{array}$ & [119] \\
\hline & Drug delivery & RAW264.7 & Electroporation & miR-21 molecular beacon & $4 \mathrm{~T} 1$ & $\begin{array}{l}\text { Realized a specific microRNA-responding delivery system } \\
\text { for visual therapy of tumors }\end{array}$ & [94] \\
\hline & Cancer target & RAW264.7 & $\begin{array}{l}\text { Membrane } \\
\text { modification }\end{array}$ & AS1411 aptamer & MDA-MB231 & $\begin{array}{l}\text { Caused remarkable tumor tissue damage and reduced the } \\
\text { percentage of proliferating Ki67-positive tumor cells }\end{array}$ & [93] \\
\hline & Gene editing & SKOV3 & Electroporation & DNA plasmid & SKOV3 & $\begin{array}{l}\text { Suppressed expression of poly(ADP-ribose) polymerase- } 1 \\
\text { (PARP-1), resulting in the induction of apoptosis in ovarian } \\
\text { cancer }\end{array}$ & [91] \\
\hline
\end{tabular}


EVs: Extracellular vesicles; MSCs: mesenchymal stem cells; DCs: dendritic cells.

the outer surface of the EVs. Instead, placing cholesterol at the three-way arrow resulted in partial loading of RNA nanoparticles into vesicles. As a result, RNA nanostructures are directionally attached to the lipid bilayer membrane of EV, and the target ligand decorates the outer surface of EVs. This directionally engineered ligand showed that the engineered EVs can deliver siRNA to target cells specifically and realize effective blocking of tumor growth ${ }^{[115]}$. Recently, $\mathrm{sgC} 8$, an aptamer of membrane-bound protein tyrosine kinase 7 , has been coupled to diacyl-lipids via PEG ligands in therapy platforms ${ }^{[200]}$. The immature dendritic cell-derived EVs are loaded with doxorubicin through electroporation, and then the EVs are functionalized by surface-targeting ligands through the hydrophobic effect ${ }^{[120]}$. This sgC8-guided exosome exhibits selective and dose-dependent cytotoxicity to human leukemia cells. In terms of the mechanism of cell internalization, studies have shown that clathrin-mediated endocytosis plays a major role in sgC8 aptamer-mediated endocytosis of various endocytosis pathways. These results suggest that targeted ligands themselves may influence exosome interactions with target cells ${ }^{[120]}$. Nevertheless, whether other ligandtarget pairs affect $\mathrm{EV}$ internalization by different cancer cells remains to be determined.

\section{Nucleic acid-functionalized extracellular vesicles for gene therapy}

Gene therapy is regarded as a possible cure to eradicate cancer and genetic diseases. The CRISPR/Cas9 system is a new gene editing tool and designed to work as a Cas9 nuclease single guide RNA (sgRNA) complex which has been widely used in life science. Recognizing the complementary 20-nucleotide genome sequence by sgRNA, Cas9 nuclease cleaves the double-stranded DNA and destroys three bases upstream of the adjacent motif of the target gene, leading to gene deletion, insertion, and mutation through error-prone non-homologous end linking or precise homologous directed repair. Although the CRISPR/Cas9 system is considered a promising gene therapy strategy, one key hurdle remains: the lack of a safe and effective way to transport the CRISPR/Cas9 system in the body. In recent years, EVs have been widely studied as promising drug delivery carriers, but their encapsulation efficiency of large nucleic acids is low. Lin et al. ${ }^{[103]}$ developed a hybrid method of exosomes and liposomes by simple incubation method. The synthesized hybrid nanoparticles effectively encapsulate the CRISPR-Cas9 plasmid, similar to liposomes. Further experiments showed that the synthesized hybrid nanoparticles could be incorporated into mesenchymal stem cells (MSCs) to express encapsulated genes that could not be transfected by liposomes alone. In another study, Kim et al. ${ }^{[91]}$ achieved tumor-targeted gene editing using tumor-derived EVs loaded with CRISPR/Cas9 plasmid by electroporation. These studies provide a new method for delivering the CRISPR/Cas9 system in vivo, which is expected to enable precise gene editing in vivo and be used in the treatment of cancer and other genetic diseases.

In addition to gene editing systems, gene therapy can also be achieved by regulating gene expression. Liu's team ${ }^{[95]}$ used molecular beacons to silence the $m i R$ 21 gene, thus enabling EV-mediated gene therapy. In earlier studies, the Kalluri group ${ }^{[98]}$ achieved targeted gene therapy for pancreatic cancer by using exosomes from normal fibroblast-like mesenchymal cells carrying interference sequences targeting oncogenic KrasG12D. Recently, the study entered a phase I 
clinical trial (ClinicalTrials.gov, Identifier: NCT03608631). Non-coding RNAs (ncRNAs) are natural tools for gene expression regulation and are also loaded into EVs for intracellular delivery and gene therapy ${ }^{[108,109,11,121]}$. Nucleic acid-functionalized EVs also show good application potential in tissue repair. Mathiyalagan et al. ${ }^{[121]}$ reported that EVs derived from $\mathrm{CD}_{3}{ }^{+}$stem cells can target recipient cells and transfer miRNA precursors to regulate gene expression. In another study, Guo et al. ${ }^{[122]}$ used MSC-derived exosomes loaded with phosphatase and tensin siRNA for spinal injury repair. MSC-derived exosomes have been reported to have a protective effect in many diseases such as myocardial infarction ${ }^{[9,123]}$, bone defects $^{[124]}$, and kidney diseases ${ }^{[225]}$ and can play a synergistic role with siRNA in tissue repair. These studies confirmed that EVs, as small RNA delivery carriers, have good potential in gene therapy. EVs have also been used to deliver large RNA. Yang et al. ${ }^{[16]}$ developed a technique for mass production of mRNAencapsulating EVs through a homemade electroporation device. A new study found that both nerve growth factor mRNA and protein delivered via EVs can effectively treat ischemic brain injury ${ }^{[00]}$. This will further promote the application of nucleic acid-functionalized EVs in the biomedical field.

\section{Nucleic acid-functionalized extracellular vesicles used in immunotherapy}

Immunotherapy has made remarkable achievements in clinical trials of malignant tumors, which brings new hope for tumor treatment. However, the suppressive state of the tumor immune microenvironment greatly limits the effect of immunotherapy. Therefore, regulating the immune state of the tumor microenvironment is of great significance to improve the effect of immunotherapy. CpG ODN can activate DCs and macrophages through TLR9, thus improving antigen presentation and immune activation effect. Yu et al. ${ }^{\left[{ }^{[7]}\right.}$ prepared exosomes from different origins and compared their physicochemical properties and delivery efficiency to verify whether EVs can effectively deliver immune-stimulating molecules to lymph nodes. It was found that EV encapsulation greatly increased the amount of internalization of immunomodulatory molecules, which induced higher tumor necrosis factor $\alpha$ (TNF- $\alpha$ ) and interleukin- 6 (IL-6) expression than free monophosphoryl lipid A (MPLA) and free CpG ODN. After subcutaneously loading CpG and MPLA exosomes, the expression of cytokines interferon- $\gamma($ IFN- $\gamma$ ) and TNF- $\alpha$ increased, and $\mathrm{T}$ cells were activated. This suggests that the delivery of immune adjuvants by extracellular vesicles is a potential immunotherapy strategy.

The nucleic acid vaccine is a new immunotherapy method. The intracellular delivery of nucleic acid and antigen expression can be effectively realized by loading the DNA or mRNA encoding antigen into EVs. In a preprint, Tsai et al. ${ }^{[126]}$ used exosome-mediated mRNA delivery as a severe acute respiratory syndrome coronavirus (2SARS-CoV-2) vaccine. The results show that the vaccine triggered long-term antiviral immune responses include cellular and humoral immunity, suggesting that exosome-based mRNA formulations represent a previously untapped platform for combating coronavirus disease 2019 (COVID19). Recently, Allele Biotechnology and Pharmaceutical ${ }^{[75]}$ announced that they have designed an induced pluripotent stem cell (iPSC) line carrying genes encoding multiple SARS-COV-2 antigen. This iPSC line can release large amounts of EVs that carry viral mRNA and proteins. Alleles indicated that the engineered cell line conquers two problems: (1) vaccines containing multiple antigens may have better performance than vaccines containing single mRNAs, such as Pfizer/biotech and Moderna vaccines; and (2) while the Pfizer/BioNTech vaccines need to be stored at $-80^{\circ} \mathrm{C}$, iPSC-derived EVs prevent messenger RNA degradation, making RNA remain intact for several months at $4{ }^{\circ} \mathrm{C}$.

\section{CHALLENGES AND PROSPECTS}

Nucleic acid-functionalized EVs show great application prospects in the biomedical field. It enables EVs to be a promising candidate in the hot areas of targeted drug delivery, gene therapy, and immunotherapy. However, some challenges to using nucleic acid-functionalized EVs remain. Firstly, the lack of research 
methods on EVs has greatly hindered the development of nucleic acid-functionalized vesicles. The low natural production rate of EVs greatly affects mass production. At the same time, EVs are heterogeneous, and it is difficult to obtain high purity homogeneity subgroups by existing isolation techniques. Although purified EVs can be isolated from cell lines secreting EVs, these EVs have immunogenic and carcinogenic potential. This greatly impedes downstream modification, quality evaluation, and clinical application. Secondly, RNA-based nucleic acid functionalization is affected by the lack of stability of RNA, which is easily destroyed and leads to the failure of functionalization. In addition to the above outstanding problems, nucleic acid-functionalized EVs are also faced with the lack of modification methods, the dilemma of selection of EVs, and the difficulty of clinical transformation. Nevertheless, nucleic acid-functionalized EVs provide a new tool for biomedicine with great potential and application prospects.

Reviewing the latest research progress, we speculate that nucleic acid-functionalized EVs will become a hot research area in the future. We boldly forecast its future research direction. The multi-functional diagnosis and treatment platform based on the programmable characteristics of the nucleic acid will realize personalized and precise treatment. Nucleic acid has programmable performance and can achieve intelligence and multi-function through sequence design. Nucleic acid-functionalized EVs enable the EVs to acquire intelligent characteristics such as stimulus response, intelligent controlled release, and therapeutic feedback. It promises to provide new strategies for personalization and precision medicine. A gene-editing system based on EVs is expected to achieve precise and efficient gene therapy. CRISPR, a gene-editing system, has made significant progress at the cellular level, showing satisfactory gene editing efficiency. However, in vivo gene editing is still hampered by the lack of delivery vectors. EVs are natural delivery carriers of bioactive molecules and have the ability to allow bioactive molecules to escape from lysosomes. Recent studies have found that EVs have tissue targeting ability such as homologous targeting. A geneediting system developed by EVs is expected to achieve accurate and efficient gene editing in vivo.

\section{DECLARATIONS}

\section{Authors' contributions}

Responsible for conceptualization: Fan Z, Wang L

Writing the manuscript: Liu C, He D

Responsible for the visualization: He D

Responsible for literature collection and collation: Cen H, Chen H, Li L, Nie G, Zhong Z, He Q, Yang X, Guo S

Responsible for financial support: Fan Z, Liu C, Wang L

Responsible for the revision: He D, Zhong Z, He Q, Liu C

All authors read and approved the final manuscript.

\section{Availability of data and materials}

Not applicable.

\section{Financial support and sponsorship}

This work was supported by the National Natural Science Foundation of China (82002253, 82104495, 81804132 \& 81803919), the Macau Young Scholars Program (AM2021023), Scientific research projects of Guangdong Bureau of traditional Chinese Medicine (No. 20200513093851), Research Fund of State Key Laboratory of Dampness Syndrome of Chinese Medicine (SZ2021ZZ21), Guangdong Basic and Applied Basic Research Foundation (2021A1515012573 and 2019A1515111108), Science and Technology Foundation of Guangzhou City (202102010257), the TCM Research Fund of Guangdong Provincial Hospital of Chinese Medicine (YN2019MJ15), and the Fund of Science and Technology Innovation Strategy of Guangdong Province (191900105). 


\section{Conflicts of interest}

All authors declared that there are no conflicts of interest.

\section{Ethical approval and consent to participate \\ Not applicable.}

\section{Consent for publication}

Not applicable.

\section{Copyright}

(c) The Author(s) 2022.

\section{REFERENCES}

1. Théry C, Zitvogel L, Amigorena S. Exosomes: composition, biogenesis and function. Nat Rev Immunol 2002;2:569-79. DOI PubMed

2. Meckes DG Jr, Shair KH, Marquitz AR, Kung CP, Edwards RH, Raab-Traub N. Human tumor virus utilizes exosomes for intercellular communication. Proc Natl Acad Sci U S A 2010;107:20370-5. DOI PubMed PMC

3. Umezu T, Ohyashiki K, Kuroda M, Ohyashiki JH. Leukemia cell to endothelial cell communication via exosomal miRNAs. Oncogene 2013;32:2747-55. DOI PubMed

4. der Pol E, Böing AN, Harrison P, Sturk A, Nieuwland R. Classification, functions, and clinical relevance of extracellular vesicles. Pharmacol Rev 2012;64:676-705. DOI PubMed

5. Herrmann IK, Wood MJA, Fuhrmann G. Extracellular vesicles as a next-generation drug delivery platform. Nat Nanotechnol 2021;16:748-59. DOI PubMed

6. Andaloussi S, Mäger I, Breakefield XO, Wood MJ. Extracellular vesicles: biology and emerging therapeutic opportunities. Nat Rev Drug Discov 2013;12:347-57. DOI PubMed

7. Li F, Zhang J, Chen A, et al. Combined transplantation of neural stem cells and bone marrow mesenchymal stem cells promotes neuronal cell survival to alleviate brain damage after cardiac arrest via microRNA-133b incorporated in extracellular vesicles. Aging (Albany NY) 2021;13:262-78. DOI PubMed PMC

8. Wu P, Zhang B, Ocansey DKW, Xu W, Qian H. Extracellular vesicles: a bright star of nanomedicine. Biomaterials 2021;269:120467. DOI PubMed

9. Liu C, Bayado N, He D, et al. Therapeutic applications of extracellular vesicles for myocardial repair. Front Cardiovasc Med 2021;8:758050. DOI PubMed PMC

10. Fan Z, Liu H, Xue Y, et al. Reversing cold tumors to hot: an immunoadjuvant-functionalized metal-organic framework for multimodal imaging-guided synergistic photo-immunotherapy. Bioact Mater 2021;6:312-25. DOI PubMed PMC

11. Akinc A, Maier MA, Manoharan M, et al. The Onpattro story and the clinical translation of nanomedicines containing nucleic acidbased drugs. Nat Nanotechnol 2019;14:1084-7. DOI PubMed

12. Chen Y, Gao P, Pan W, et al. Polyvalent spherical aptamer engineered macrophages: X-ray-actuated phenotypic transformation for tumor immunotherapy. Chem Sci 2021;12:13817-24. DOI PubMed PMC

13. Gao P, Pan W, Li N, Tang B. Fluorescent probes for organelle-targeted bioactive species imaging. Chem Sci 2019;10:6035-71. DOI PubMed PMC

14. Wu Y, Zheng J, Zeng Q, Zhang T, Xing D. Light-responsive charge-reversal nanovector for high-efficiency in vivo CRISPR/Cas9 gene editing with controllable location and time. Nano Res 2020;13:2399-406. DOI

15. Wang X, Wang X, Yue Q, et al. Liquid exfoliation of TiN nanodots as novel sonosensitizers for photothermal-enhanced sonodynamic therapy against cancer. Nano Today 2021;39:101170. DOI

16. Zhou L, Pi W, Hao M, et al. An injectable and biodegradable nano-photothermal DNA hydrogel enhances penetration and efficacy of tumor therapy. Biomater Sci 2021;9:4904-21. DOI PubMed

17. Lu C, Fan Z, Xing D. Photo-enhancement of macrophage phagocytic activity via Rac1-mediated signaling pathway: implications for bacterial infection. Int J Biochem Cell Biol 2016;78:206-16. DOI PubMed

18. Liu Y, Fan Z, Zhou Y, et al. Self-circulating electrochemiluminescence chip for sensitive detection of circulating tumour nucleic acids in blood. Sens Actuators B Chem 2019;301:127088. DOI

19. Zhao Z, Tan Q, Zhan X, et al. Cascaded electrochemiluminescence signal amplifier for the detection of telomerase activity from tumor cells and tissues. Theranostics 2018;8:5625-33. DOI PubMed PMC

20. Oh YK, Park TG. siRNA delivery systems for cancer treatment. Adv Drug Deliv Rev 2009;61:850-62. DOI PubMed

21. Gao P, Wang M, Wan X, et al. A COF-based anti-interference nanoplatform for intracellular nucleic acid imaging. Chem Commun (Camb) 2020;56:14267-70. DOI PubMed

22. Gao P, Wei R, Chen Y, et al. Multicolor covalent organic framework-DNA nanoprobe for fluorescence imaging of biomarkers with different locations in living cells. Anal Chem 2021;93:13734-41. DOI PubMed

23. Gao P, Shen X, Liu X, et al. Nucleic acid-gated covalent organic frameworks for cancer-specific imaging and drug release. Anal 
Chem 2021;93:11751-7. DOI PubMed

24. Xu CF, Iqbal S, Shen S, Luo YL, Yang X, Wang J. Development of "CLAN" nanomedicine for nucleic acid therapeutics. Small 2019;15:e1900055. DOI PubMed

25. Bonanni A, Ambrosi A, Pumera M. Nucleic acid functionalized graphene for biosensing. Chemistry 2012;18:1668-73. DOI PubMed

26. Sacks D, Baxter B, Campbell BCV, et al; From the American Association of Neurological Surgeons (AANS), American Society of Neuroradiology (ASNR), Cardiovascular and Interventional Radiology Society of Europe (CIRSE), Canadian Interventional Radiology Association (CIRA), Congress of Neurological Surgeons (CNS), European Society of Minimally Invasive Neurological Therapy (ESMINT), European Society of Neuroradiology (ESNR), European Stroke Organization (ESO), European Stroke Organization (ESO), European Stroke Organization (ESO), Society of NeuroInterventional Surgery (SNIS), and World Stroke Organization (WSO). Multisociety consensus quality improvement revised consensus statement for endovascular therapy of acute ischemic stroke. Int $J$ Stroke 2018;13:612-32. DOI PubMed

27. Tapsin S, Sun M, Shen Y, et al. Genome-wide identification of natural RNA aptamers in prokaryotes and eukaryotes. Nat Commun 2018;9:1289. DOI PubMed PMC

28. Zhu G, Chen X. Aptamer-based targeted therapy. Adv Drug Deliv Rev 2018;134:65-78. DOI PubMed PMC

29. Nimjee SM, White RR, Becker RC, Sullenger BA. Aptamers as therapeutics. Annu Rev Pharmacol Toxicol 2017;57:61-79. DOI PubMed PMC

30. Gefen T, Castro I, Muharemagic D, Puplampu-Dove Y, Patel S, Gilboa E. A TIM-3 oligonucleotide aptamer enhances T cell functions and potentiates tumor immunity in mice. Mol Ther 2017;25:2280-8. DOI PubMed PMC

31. Panigaj M, Johnson MB, Ke W, et al. Aptamers as modular components of therapeutic nucleic acid nanotechnology. ACS Nano 2019;13:12301-21. DOI PubMed PMC

32. Wang J, Gao T, Luo Y, et al. In vitro selection of a DNA aptamer by cell-SELEX as a molecular probe for cervical cancer recognition and imaging. J Mol Evol 2019;87:72-82. DOI PubMed

33. Liu M, Wang Z, Tan T, et al. An aptamer-based probe for molecular subtyping of breast cancer. Theranostics 2018;8:5772-83. DOI PubMed PMC

34. Wang L, Lee JY, Gao L, et al. A DNA aptamer for binding and inhibition of DNA methyltransferase 1. Nucleic Acids Res 2019;47:11527-37. DOI PubMed PMC

35. Zheng J, Zhao S, Yu X, Huang S, Liu HY. Simultaneous targeting of CD44 and EpCAM with a bispecific aptamer effectively inhibits intraperitoneal ovarian cancer growth. Theranostics 2017;7:1373-88. DOI PubMed PMC

36. Li Y, Peng Y, Tan Y, et al. A new paradigm for artesunate anticancer function: considerably enhancing the cytotoxicity via conjugating artesunate with aptamer. Signal Transduct Target Ther 2021;6:327. DOI PubMed PMC

37. Mergny JL, Sen D. DNA quadruple helices in nanotechnology. Chem Rev 2019;119:6290-325. DOI PubMed

38. Krishnan Y, Seeman NC. Introduction: nucleic acid nanotechnology. Chem Rev 2019;119:6271-2. DOI PubMed

39. Hu Q, Li H, Wang L, Gu H, Fan C. DNA nanotechnology-enabled drug delivery systems. Chem Rev 2019;119:6459-506. DOI PubMed

40. Hong F, Zhang F, Liu Y, Yan H. DNA origami: scaffolds for creating higher order structures. Chem Rev 2017;117:12584-640. DOI PubMed

41. Jiang Q, Liu S, Liu J, Wang ZG, Ding B. Rationally designed DNA-origami nanomaterials for drug delivery in vivo. Adv Mater 2019;31:e1804785. DOI PubMed

42. Ge Z, Guo L, Wu G, et al. DNA origami-enabled engineering of ligand-drug conjugates for targeted drug delivery. Small 2020;16:e1904857. DOI PubMed

43. Zhang T, Hartl C, Frank K, et al. 3D DNA origami crystals. Adv Mater 2018;30:e1800273. DOI PubMed

44. Li S, Jiang Q, Liu S, et al. A DNA nanorobot functions as a cancer therapeutic in response to a molecular trigger in vivo. Nat Biotechnol 2018:36:258-64. DOI PubMed

45. Ma W, Zhan Y, Zhang Y, et al. An intelligent DNA nanorobot with in vitro enhanced protein lysosomal degradation of HER2. Nano Lett 2019;19:4505-17. DOI PubMed

46. Jiang Q, Song C, Nangreave J, et al. DNA origami as a carrier for circumvention of drug resistance. J Am Chem Soc 2012;134:13396403. DOI PubMed

47. Jiang Q, Xu X, Yin PA, et al. Circularly polarized luminescence of achiral cyanine molecules assembled on DNA templates. $J$ Am Chem Soc 2019;141:9490-4. DOI PubMed

48. Ijäs H, Shen B, Heuer-Jungemann A, et al. Unraveling the interaction between doxorubicin and DNA origami nanostructures for customizable chemotherapeutic drug release. Nucleic Acids Res 2021;49:3048-62. DOI PubMed PMC

49. Xu T, Yu S, Sun Y, et al. DNA origami frameworks enabled self-protective siRNA delivery for dual enhancement of chemophotothermal combination therapy. Small 2021;17:e2101780. DOI PubMed

50. Wang Z, Song L, Liu Q, et al. A tubular DNA nanodevice as a siRNA/chemo-drug co-delivery vehicle for combined cancer therapy. Angew Chem Int Ed Engl 2021;60:2594-8. DOI PubMed

51. Wang ST, Gray MA, Xuan S, et al. DNA origami protection and molecular interfacing through engineered sequence-defined peptoids. Proc Natl Acad Sci U S A 2020;117:6339-48. DOI PubMed PMC

52. Liu J, Song L, Liu S, et al. A DNA-based nanocarrier for efficient gene delivery and combined cancer therapy. Nano Lett 2018;18:3328-34. DOI PubMed

53. Wu T, Liu J, Liu M, et al. A nanobody-conjugated DNA nanoplatform for targeted platinum-drug delivery. Angew Chem 2019;131:14362-6. DOI PubMed 
54. Liu X, Xu X, Zhou Y, Zhang N, Jiang W. Multifunctional molecular beacons-modified gold nanoparticle as a nanocarrier for synergistic inhibition and in situ imaging of drug-resistant-related mRNAs in living cells. ACS Appl Mater Interfaces 2019;11:3554855. DOI PubMed

55. Ma Y, Wang Z, Zhang M, et al. A telomerase-specific doxorubicin-releasing molecular beacon for cancer theranostics. Angew Chem Int Ed Engl 2016;55:3304-8. DOI PubMed

56. Wang J, Chao J, Liu H, et al. Clamped hybridization chain reactions for the self-assembly of patterned DNA hydrogels. Angew Chem Int Ed Engl 2017;56:2171-5. DOI PubMed

57. Zhang J, Guo Y, Pan G, et al. Injectable drug-conjugated DNA hydrogel for local chemotherapy to prevent tumor recurrence. ACS Appl Mater Interfaces 2020;12:21441-9. DOI PubMed

58. High KA, Roncarolo MG. Gene therapy. N Engl J Med 2019;381:455-64. DOI PubMed

59. Kulkarni JA, Witzigmann D, Thomson SB, et al. The current landscape of nucleic acid therapeutics. Nat Nanotechnol 2021;16:63043. DOI PubMed

60. Kusano KF, Pola R, Murayama T, et al. Sonic hedgehog myocardial gene therapy: tissue repair through transient reconstitution of embryonic signaling. Nat Med 2005;11:1197-204. DOI PubMed

61. Fellmann C, Gowen BG, Lin PC, Doudna JA, Corn JE. Cornerstones of CRISPR-Cas in drug discovery and therapy. Nat Rev Drug Discov 2017;16:89-100. DOI PubMed PMC

62. Bartok E, Hartmann G. Immune sensing mechanisms that discriminate self from altered self and foreign nucleic acids. Immunity 2020;53:54-77. DOI PubMed PMC

63. Deng C, Zhang Q, Jia M, et al. Tumors and their microenvironment dual-targeting chemotherapy with local immune adjuvant therapy for effective antitumor immunity against breast cancer. Adv Sci (Weinh) 2019;6:1801868. DOI PubMed PMC

64. Lai C, Duan S, Ye F, et al. The enhanced antitumor-specific immune response with mannose- and CpG-ODN-coated liposomes delivering TRP2 peptide. Theranostics 2018;8:1723-39. DOI PubMed PMC

65. Moreira D, Adamus T, Zhao X, et al. STAT3 inhibition combined with CpG immunostimulation activates antitumor immunity to eradicate genetically distinct castration-resistant prostate cancers. Clin Cancer Res 2018;24:5948-62. DOI PubMed PMC

66. Charlebois R, Allard B, Allard D, et al. PolyI:C and CpG synergize with anti-ErbB2 mAb for treatment of breast tumors resistant to immune checkpoint inhibitors. Cancer Res 2017;77:312-9. DOI PubMed

67. Sagiv-Barfi I, Czerwinski DK, Levy S, et al. Eradication of spontaneous malignancy by local immunotherapy. Sci Transl Med 2018;10:eaan4488. DOI PubMed PMC

68. Ni Q, Zhang F, Liu Y, et al. A bi-adjuvant nanovaccine that potentiates immunogenicity of neoantigen for combination immunotherapy of colorectal cancer. Sci Adv 2020;6:eaaw6071. DOI PubMed PMC

69. Morishita M, Takahashi Y, Matsumoto A, Nishikawa M, Takakura Y. Exosome-based tumor antigens-adjuvant co-delivery utilizing genetically engineered tumor cell-derived exosomes with immunostimulatory CpG DNA. Biomaterials 2016;111:55-65. DOI PubMed

70. Yildirim M, Yildirim TC, Turay N, et al. TLR ligand loaded exosome mediated immunotherapy of established mammary Tumor in mice. Immunol Lett 2021;239:32-41. DOI PubMed

71. Naour J, Galluzzi L, Zitvogel L, Kroemer G, Vacchelli E. Trial watch: TLR3 agonists in cancer therapy. Oncoimmunology 2020;9:1771143. DOI PubMed PMC

72. Qiu N, Wang G, Wang J, et al. Tumor-associated macrophage and tumor-cell dually transfecting polyplexes for efficient interleukin12 cancer gene therapy. Adv Mater 2021;33:e2006189. DOI PubMed

73. Chiocca EA, Yu JS, Lukas RV, et al. Regulatable interleukin-12 gene therapy in patients with recurrent high-grade glioma: results of a phase 1 trial. Sci Transl Med 2019;11:eaaw5680. DOI PubMed PMC

74. Qin F, Xia F, Chen H, et al. A guide to nucleic acid vaccines in the prevention and treatment of infectious diseases and cancers: from basic principles to current applications. Front Cell Dev Biol 2021;9:633776. DOI PubMed PMC

75. Ho PP, Lahey LJ, Mourkioti F, et al. Engineered DNA plasmid reduces immunity to dystrophin while improving muscle force in a model of gene therapy of Duchenne dystrophy. Proc Natl Acad Sci U S A 2018;115:E9182-91. DOI PubMed PMC

76. Parks RJ, Gussoni E. Building immune tolerance through DNA vaccination. Proc Natl Acad Sci U S A 2018;115:9652-4. DOI PubMed PMC

77. Jackson NAC, Kester KE, Casimiro D, Gurunathan S, DeRosa F. The promise of mRNA vaccines: a biotech and industrial perspective. NPJ Vaccines 2020;5:11. DOI PubMed PMC

78. Espeseth AS, Cejas PJ, Citron MP, et al. Modified mRNA/lipid nanoparticle-based vaccines expressing respiratory syncytial virus F protein variants are immunogenic and protective in rodent models of RSV infection. NPJ Vaccines 2020;5:16. DOI PubMed PMC

79. Van Hoecke L, Verbeke R, Dewitte H, et al. mRNA in cancer immunotherapy: beyond a source of antigen. Mol Cancer 2021;20:48. DOI PubMed PMC

80. Heine A, Juranek S, Brossart P. Clinical and immunological effects of mRNA vaccines in malignant diseases. Mol Cancer 2021;20:52. DOI PubMed PMC

81. Wang Y, Zhang Z, Luo J, Han X, Wei Y, Wei X. mRNA vaccine: a potential therapeutic strategy. Mol Cancer 2021;20:33. DOI PubMed PMC

82. Miao L, Zhang Y, Huang L. mRNA vaccine for cancer immunotherapy. Mol Cancer 2021;20:41. DOI PubMed PMC

83. Park JW, Lagniton PNP, Liu Y, Xu RH. mRNA vaccines for COVID-19: what, why and how. Int J Biol Sci 2021;17:1446-60. DOI PubMed PMC

84. Polack FP, Thomas SJ, Kitchin N, et al; C4591001 Clinical Trial Group. Safety and efficacy of the BNT162b2 mRNA Covid-19 
vaccine. $N$ Engl J Med 2020;383:2603-15. DOI PubMed PMC

85. Vrieze J. Pfizer's vaccine raises allergy concerns. Science 2021;371:10-1. DOI PubMed

86. Hall VJ, Foulkes S, Saei A, et al. COVID-19 vaccine coverage in health-care workers in England and effectiveness of BNT162b2 mRNA vaccine against infection (SIREN): a prospective, multicentre, cohort study. Lancet 2021;397:1725-35. DOI PubMed PMC

87. Haas EJ, Angulo FJ, Mclaughlin JM, et al. Impact and effectiveness of mRNA BNT162b2 vaccine against SARS-CoV-2 infections and COVID-19 cases, hospitalisations, and deaths following a nationwide vaccination campaign in Israel: an observational study using national surveillance data. Lancet 2021;397:1819-29. DOI PubMed PMC

88. Alberer M, Gnad-vogt U, Hong HS, et al. Safety and immunogenicity of a mRNA rabies vaccine in healthy adults: an open-label, non-randomised, prospective, first-in-human phase 1 clinical trial. Lancet 2017;390:1511-20. DOI PubMed

89. Kojima R, Bojar D, Rizzi G, et al. Designer exosomes produced by implanted cells intracerebrally deliver therapeutic cargo for Parkinson's disease treatment. Nat Commun 2018;9:1305. DOI PubMed PMC

90. Yang J, Wu S, Hou L, et al. Therapeutic effects of simultaneous delivery of nerve growth factor mRNA and protein via exosomes on cerebral ischemia. Mol Ther Nucleic Acids 2020;21:512-22. DOI PubMed PMC

91. Kim SM, Yang Y, Oh SJ, Hong Y, Seo M, Jang M. Cancer-derived exosomes as a delivery platform of CRISPR/Cas9 confer cancer cell tropism-dependent targeting. J Control Release 2017;266:8-16. DOI PubMed

92. Didiot MC, Hall LM, Coles AH, et al. Exosome-mediated delivery of hydrophobically modified siRNA for huntingtin mRNA silencing. Mol Ther 2016;24:1836-47. DOI PubMed PMC

93. Wan Y, Wang L, Zhu C, et al. Aptamer-conjugated extracellular nanovesicles for targeted drug delivery. Cancer Res 2018;78:798808. DOI PubMed PMC

94. Fan Z, Xiao K, Lin J, Liao Y, Huang X. Functionalized DNA enables programming exosomes/vesicles for tumor imaging and therapy. Small 2019;15:e1903761. DOI PubMed

95. Wang J, Chen P, Dong Y, et al. Designer exosomes enabling tumor targeted efficient chemo/gene/photothermal therapy. Biomaterials 2021;276:121056. DOI PubMed

96. Zhao L, Gu C, Gan Y, Shao L, Chen H, Zhu H. Exosome-mediated siRNA delivery to suppress postoperative breast cancer metastasis. J Control Release 2020;318:1-15. DOI PubMed

97. Yu G, Jung H, Kang YY, Mok H. Comparative evaluation of cell- and serum-derived exosomes to deliver immune stimulators to lymph nodes. Biomaterials 2018;162:71-81. DOI PubMed

98. Kamerkar S, LeBleu VS, Sugimoto H, et al. Exosomes facilitate therapeutic targeting of oncogenic KRAS in pancreatic cancer. Nature 2017;546:498-503. DOI PubMed PMC

99. Zhupanyn P, Ewe A, Büch T, et al. Extracellular vesicle (ECV)-modified polyethylenimine (PEI) complexes for enhanced siRNA delivery in vitro and in vivo. J Control Release 2020;319:63-76. DOI PubMed

100. Lamichhane TN, Jeyaram A, Patel DB, et al. Oncogene knockdown via active loading of small RNAs into extracellular vesicles by sonication. Cell Mol Bioeng 2016;9:315-24. DOI PubMed PMC

101. Wang H, He D, Wan K, et al. In situ multiplex detection of serum exosomal microRNAs using an all-in-one biosensor for breast cancer diagnosis. Analyst 2020;145:3289-96. DOI PubMed

102. Lee JH, Kim JA, Kwon MH, Kang JY, Rhee WJ. In situ single step detection of exosome microRNA using molecular beacon. Biomaterials 2015;54:116-25. DOI PubMed

103. Lin Y, Wu J, Gu W, et al. Exosome-liposome hybrid nanoparticles deliver CRISPR/Cas9 system in MSCs. Adv Sci (Weinh) 2018;5:1700611. DOI PubMed PMC

104. Stremersch S, Vandenbroucke RE, Van Wonterghem E, Hendrix A, De Smedt SC, Raemdonck K. Comparing exosome-like vesicles with liposomes for the functional cellular delivery of small RNAs. J Control Release 2016;232:51-61. DOI PubMed

105. Yang X, Xie B, Peng H, et al. Eradicating intracellular MRSA via targeted delivery of lysostaphin and vancomycin with mannosemodified exosomes. J Control Release 2021;329:454-67. DOI PubMed

106. An Y, Jin T, Zhu Y, Zhang F, He P. An ultrasensitive electrochemical aptasensor for the determination of tumor exosomes based on click chemistry. Biosens Bioelectron 2019;142:111503. DOI PubMed

107. Smyth T, Petrova K, Payton NM, et al. Surface functionalization of exosomes using click chemistry. Bioconjug Chem 2014;25:177784. DOI PubMed PMC

108. Wang B, Yao K, Huuskes BM, et al. Mesenchymal stem cells deliver exogenous microRNA-let7c via exosomes to attenuate renal fibrosis. Mol Ther 2016;24:1290-301. DOI PubMed PMC

109. Yu X, Bai Y, Han B, et al. Extracellular vesicle-mediated delivery of circDYM alleviates CUS-induced depressive-like behaviours. $J$ Extracell Vesicles 2022;11:e12185. DOI PubMed PMC

110. Wang Y, Chen X, Tian B, et al. Nucleolin-targeted extracellular vesicles as a versatile platform for biologics delivery to breast cancer. Theranostics 2017;7:1360-72. DOI PubMed PMC

111. Reshke R, Taylor JA, Savard A, et al. Reduction of the therapeutic dose of silencing RNA by packaging it in extracellular vesicles via a pre-microRNA backbone. Nat Biomed Eng 2020;4:52-68. DOI PubMed

112. O'Loughlin AJ, Mäger I, de Jong OG, et al. Functional delivery of lipid-conjugated siRNA by extracellular vesicles. Mol Ther 2017;25:1580-7. DOI PubMed PMC

113. Biscans A, Haraszti RA, Echeverria D, et al. Hydrophobicity of lipid-conjugated siRNAs predicts productive loading to small extracellular vesicles. Mol Ther 2018;26:1520-8. DOI PubMed PMC

114. Zheng Z, Li Z, Xu C, Guo B, Guo P. Folate-displaying exosome mediated cytosolic delivery of siRNA avoiding endosome trapping. J Control Release 2019;311-312:43-9. DOI PubMed PMC 
115. Pi F, Binzel DW, Lee TJ, et al. Nanoparticle orientation to control RNA loading and ligand display on extracellular vesicles for cancer regression. Nat Nanotechnol 2018;13:82-9. DOI PubMed PMC

116. Yang Z, Shi J, Xie J, et al. Large-scale generation of functional mRNA-encapsulating exosomes via cellular nanoporation. Nat Biomed Eng 2020;4:69-83. DOI PubMed PMC

117. Zhang S, Dong Y, Wang Y, et al. Selective encapsulation of therapeutic mRNA in engineered extracellular vesicles by DNA aptamer. Nano Lett 2021;21:8563-70. DOI PubMed

118. Sedlik C, Vigneron J, Torrieri-Dramard L, et al. Different immunogenicity but similar antitumor efficacy of two DNA vaccines coding for an antigen secreted in different membrane vesicle-associated forms. J Extracell Vesicles 2014;3:24646. DOI PubMed PMC

119. Kanada M, Kim BD, Hardy JW, et al. Microvesicle-mediated delivery of minicircle DNA results in effective gene-directed enzyme prodrug cancer therapy. Mol Cancer Ther 2019;18:2331-42. DOI PubMed PMC

120. Zou J, Shi M, Liu X, et al. Aptamer-functionalized exosomes: elucidating the cellular uptake mechanism and the potential for cancertargeted chemotherapy. Anal Chem 2019;91:2425-30. DOI PubMed PMC

121. Mathiyalagan P, Sahoo S. Exosomes-based gene therapy for microRNA delivery. Methods Mol Biol 2017;1521:139-52. DOI PubMed PMC

122. Guo S, Perets N, Betzer O, et al. Intranasal delivery of mesenchymal stem cell derived exosomes loaded with phosphatase and tensin homolog siRNA repairs complete spinal cord injury. ACS Nano 2019;13:10015-28. DOI PubMed

123. Tang J, Cui X, Zhang Z, et al. Injection-free delivery of MSC-derived extracellular vesicles for myocardial infarction therapeutics. Adv Healthc Mater 2021:e2100312. DOI PubMed

124. Zhang Y, Xie Y, Hao Z, et al. Umbilical mesenchymal stem cell-derived exosome-encapsulated hydrogels accelerate bone repair by enhancing angiogenesis. ACS Appl Mater Interfaces 2021;13:18472-87. DOI PubMed

125. Gang D, Yu CJ, Zhu S, Zhu P, Nasser MI. Application of mesenchymal stem cell-derived exosomes in kidney diseases. Cell Immunol 2021;364:104358. DOI PubMed

126. Tsai SJ, Guo C, Sedgwick A, et al. Exosome-mediated mRNA delivery for SARS-CoV-2 vaccination. bioRxiv 2021. DOI 